\title{
Influence of thermomechanical processing on shear bands formation and magnetic properties of a 3\% Si non-oriented electrical steel
}

\author{
Sara Silva Ferreira de Dafé ${ }^{\mathrm{a}, *}$, Sebastião da Costa Paolinelli ${ }^{\mathrm{b}}$, André Barros Cota ${ }^{\mathrm{a}}$ \\ a Physics Department, Federal University of Ouro Preto, Campus Universitário, Ouro Preto, MG 35400000, Brazil \\ ${ }^{\mathrm{b}}$ Research Department, ArcelorMittal Inox Brasil, Praça Primeiro de Maio, 9 Timóteo, MG 35180018, Brazil
}

\section{A R T I C L E I N F O}

\section{Article history:}

Received 1 February 2011

Received in revised form

11 July 2011

Available online 26 July 2011

\section{Keywords:}

Non-oriented silicon steel

Shear band

Texture

Hot band grain size

Cold strain

Magnetic property

\begin{abstract}
A B S T R A C T
The effect of thermomechanical processing on the formation of shear bands and on the magnetic properties of a $3.0 \mathrm{wt} \%$ silicon non-oriented steel was investigated by hot rolling samples with different thicknesses at different temperatures, in order to obtain a variation in hot band grain size and cold strain. All the samples were processed in a single-stage cold rolling and finally annealed at $1020{ }^{\circ} \mathrm{C}$. It was found that the increase of the hot band grain size decreases the $\gamma$ fiber volume fraction and increases the $\eta$ fiber volume fraction after the final annealing. The increase of the cold strain strongly contributed to this result. A good combination of intense generation of shear bands, and proper crystallographic texture, due to higher nucleation of grains with favorable orientations to magnetization in these bands, can be obtained for the samples hot rolled at 1000 and $1120{ }^{\circ} \mathrm{C}$ and submitted to cold strain of $64.3 \%$ and $72.2 \%$ respectively. However the best combination of $B_{50}, W_{15 / 60}$ and $\mu_{\mathrm{r}}$ can be obtained by hot rolling the samples at $1000{ }^{\circ} \mathrm{C}$ to the thickness of $1.4 \mathrm{~mm}$, corresponding to $64.3 \%$ of cold strain.
\end{abstract}

(c) 2011 Elsevier B.V. All rights reserved.

\section{Introduction}

Optimizing the motors and generators performance depends on the use of grain non-oriented silicon steels with high permeability and low core loss. These properties are achieved by controlling the chemical composition and thermomechanical processing conditions, which influence the microstructure and the crystallographic texture [1-3].

At the final annealing stage the nucleation of grains with Goss ( $\left.\begin{array}{lll}1 & 1 & 0\end{array}\right)\left[\begin{array}{lll}0 & 0 & 1\end{array}\right]$ and Cube $\left(\begin{array}{lll}1 & 0 & 0\end{array}\right)\left[\begin{array}{lll}0 & 0 & 1\end{array}\right]$ orientations at shear bands present in the deformed structure benefit the magnetization process [4-6]. These bands correspond to narrow regions of intense shear, formed by very thin and elongated cells. They are independent of the grain structure and its crystallography, but are more frequent in highly cold deformed metals and coarse grains. In cold rolled materials, the shear bands typically occur at $35^{\circ}$ from the rolling direction and can exceed several grains through the sample [6,7].

The cold rolling process enhances $\alpha\left\{\begin{array}{llllll}h & k & l\end{array}\right\}\langle 1 \quad 0\rangle$ and $\gamma\left\{\begin{array}{lll}1 & 1 & 1\end{array}\right\}\langle u \quad v \quad w\rangle$ fibers. However, the recrystallization crystallographic texture will arise from rolling crystallographic texture heterogeneities. The strengthening of the $\alpha$ fiber is harmful because this crystallographic texture stores little energy during

\footnotetext{
* Corresponding author. Tel.: +55 3134091772.

E-mail address: saradafe@gmail.com (S.S.F. de Dafé).
}

cold rolling and provides $\gamma$ fiber grain nucleation in the interfaces with grains that have orientations belonging to $\gamma$ fiber $[2,3]$. On the other hand, the $\gamma$ fiber volume fraction increase during cold rolling is beneficial because these grains result in the Goss texture after the final annealing [4].

The addition of large amounts of solute, the presence of large grains in the structure before cold rolling, high strain and low temperatures promote the occurrence of shear bands in the deformed material $[8,9]$. The development of shear bands has a strong effect not only on the work hardening and the evolution of deformation texture, but also on the nucleation and grain growth during subsequent recrystallization. Therefore, to obtain a better understanding of deformation and recrystallization phenomena and correlation between them is essential to have a better understanding about the formation of these bands.

This work evaluates the influence of thermomechanical processing, by which were obtained hot rolled samples with different grain sizes and thicknesses, on the formation of shear bands and magnetic properties of non-oriented grain steel with 3\% Si.

\section{Material and methods}

Samples of a non-oriented grain steel of $28 \mathrm{~mm}$ thickness with 3.0\% Si, $0.004 \% \mathrm{C}$ and $0.55 \% \mathrm{Mn}$ were produced in ArcelorMittal Inox Brazil and taken after roughing, reheated at $1150^{\circ} \mathrm{C}$ for $120 \mathrm{~s}$ and rolled with seven passes to $2.2,1.8,1.4$ and $1.1 \mathrm{~mm}$ thicknesses in a 
Fenn pilot reversing mill at temperatures of 920, 960, 1000, 1040, 1080 and $1120^{\circ} \mathrm{C}$, with heating interpasses. After rolling of all the samples, they remained at $550{ }^{\circ} \mathrm{C}$ for $2 \mathrm{~h}$ and were then cooled in air

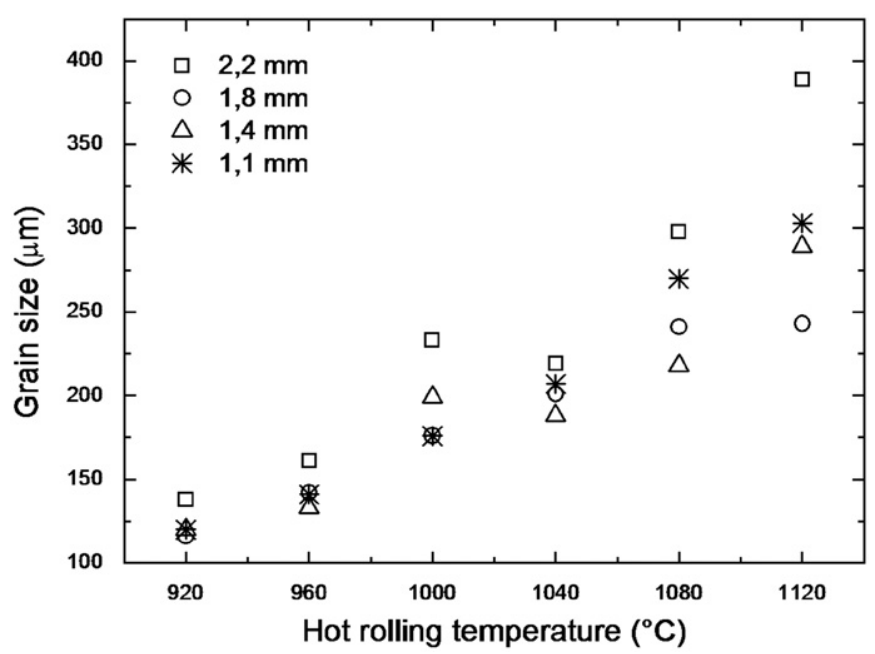

Fig. 1. Grain size as a function of hot rolling temperature for the samples rolled to different thicknesses.

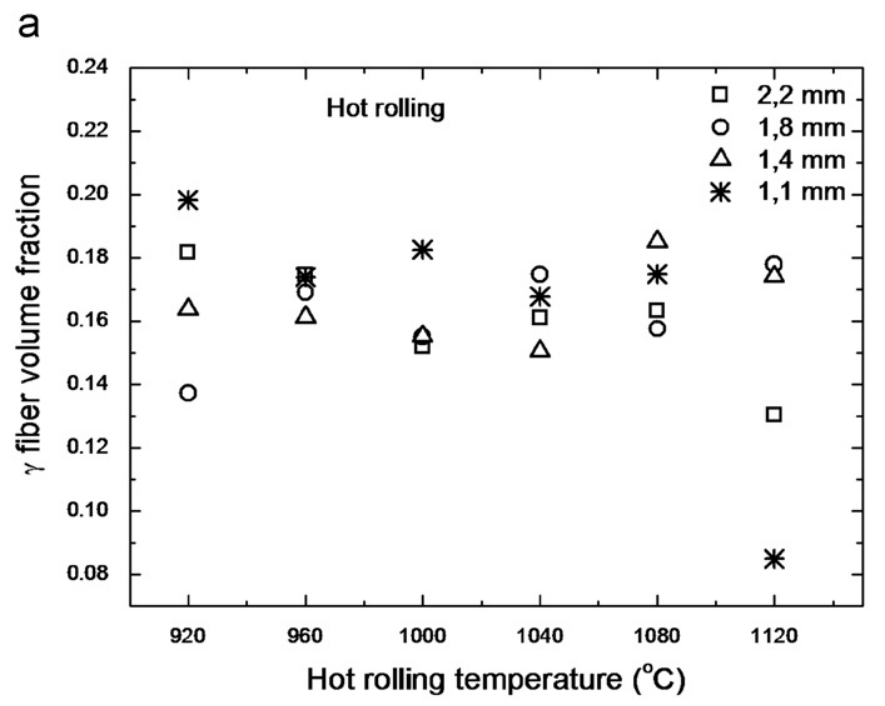

b

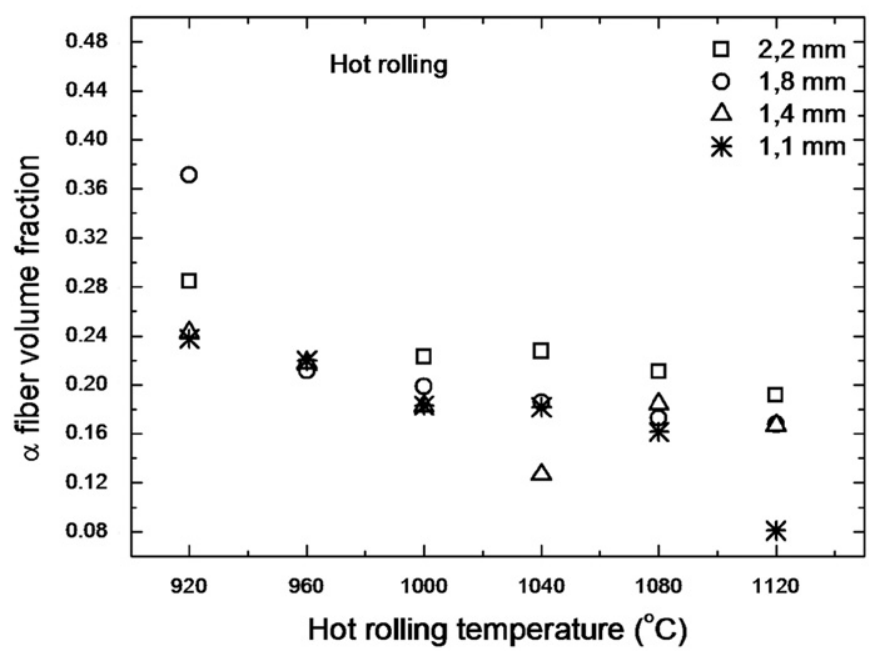

Fig. 2. $\gamma$ (a) and $\alpha$ (b) fiber volume fractions as a function of hot rolling temperature, for samples hot rolled to different thicknesses. to simulate the coiling conditions. Following this, the samples were cold rolled to $0.50 \mathrm{~mm}$ by a single-stage process and finally annealed at $1020^{\circ} \mathrm{C}$ for $30 \mathrm{~s}$. To evaluate the recrystallization

a

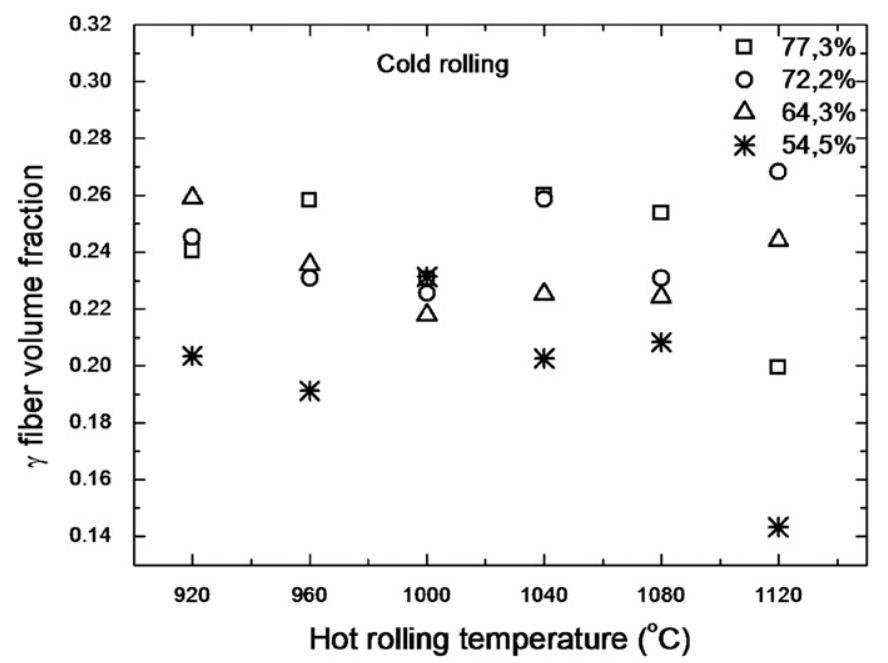

b

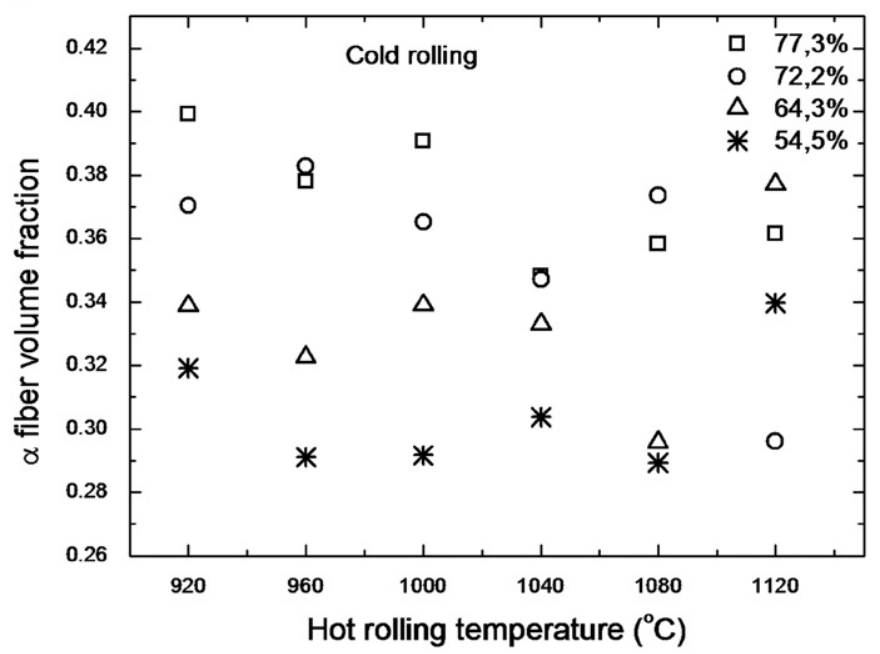

Fig. 3. $\gamma$ (a) and $\alpha$ (b) fiber volume fractions as functions of hot rolling temperature and strain degree for cold rolled samples.

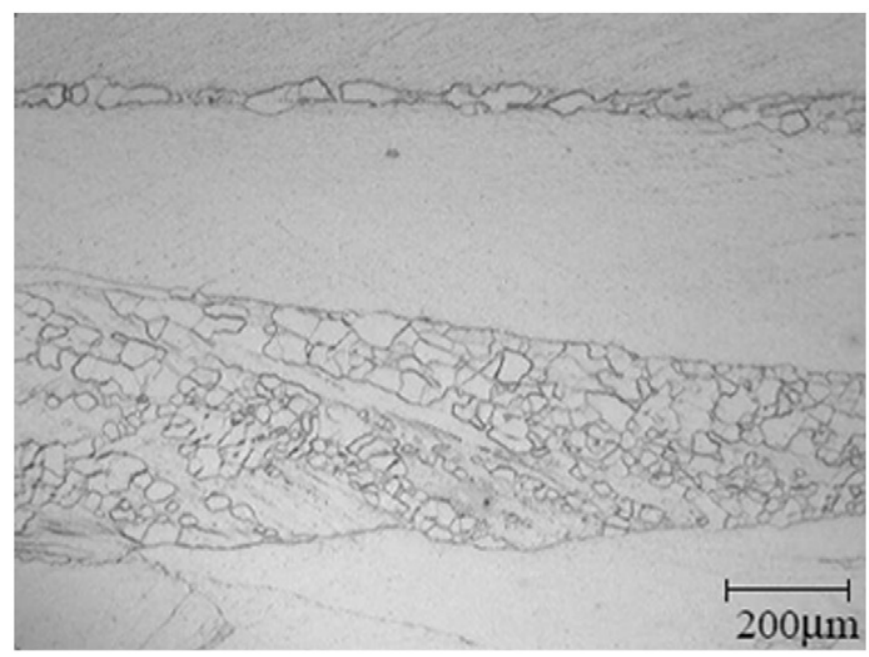

Fig. 4. Sample hot rolled at $1040{ }^{\circ} \mathrm{C}$ to $1.8 \mathrm{~mm}$ thick and then cold rolled and annealed at $700{ }^{\circ} \mathrm{C}$ for $30 \mathrm{~s}$ (section parallel to the rolling direction). 
evolution and the intensity of the shear bands formed in each sample, annealing with partial recrystallization was carried out at the temperatures $620,660,700,740$ and $780{ }^{\circ} \mathrm{C}$ for $30 \mathrm{~s}$.

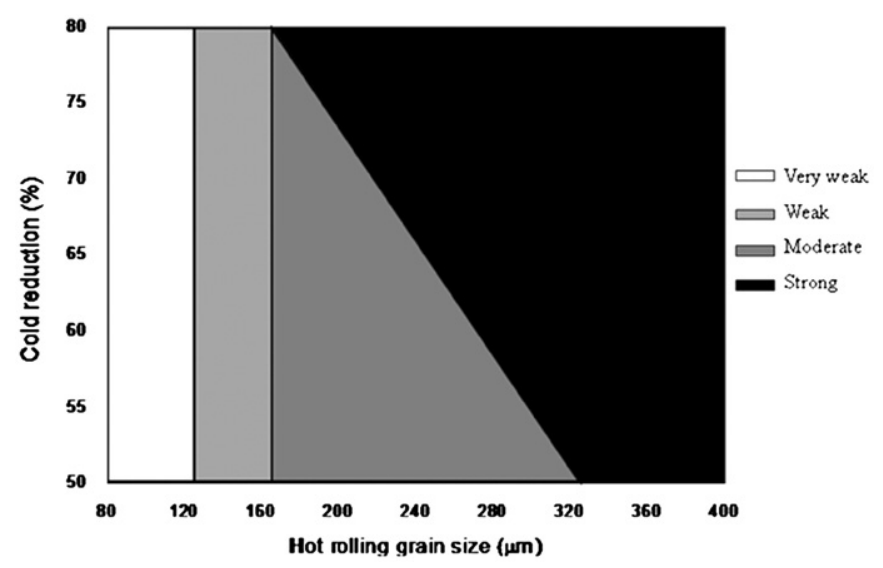

Fig. 5. Intensity of shear band formation as functions of grain size of hot rolled steel and the cold strain degree.

a

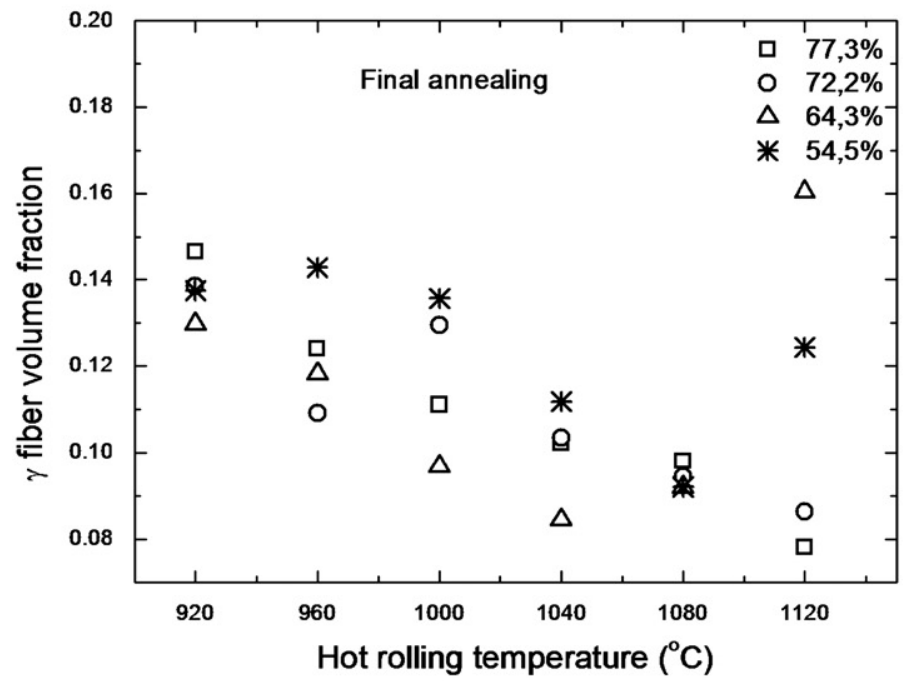

C

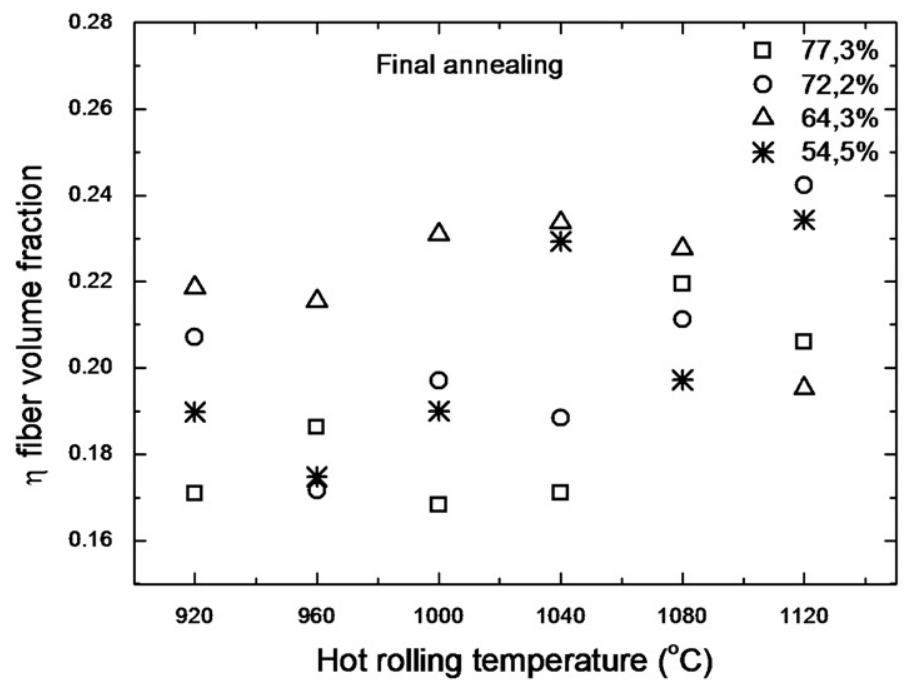

The grain size was determined by optical metallography. The crystallographic orientation and volume fractions of fiber and texture components were obtained by X-ray diffraction and Electron Back-Scattering diffraction (EBSD). The presence of shear bands was evaluated by light microscopy of samples submitted to annealing at intermediate temperatures. Magnetic induction at $5000 \mathrm{~A} / \mathrm{m}\left(B_{50}\right)$, core losses at $1.5 \mathrm{~T}$ and $60 \mathrm{~Hz}\left(W_{1.5}\right)$ and magnetic permeability at $1.5 \mathrm{~T} / 60 \mathrm{~Hz}$ were measured in the rolling direction using a single-sheet tester of a Brockhaus MPG100D.

\section{Results and discussion}

The microstructural evolution of hot rolled samples shows that a higher hot rolling temperature resulted in a larger grain size for all thicknesses, due to static recrystallization and grain growth between the passes favored by the use of the reversible rolling process with heating between the passes (Fig. 1). The influence of the hot rolling temperature on the values of $\gamma$ fiber volume fraction was not significant (Fig. 2a) and a tendency was observed for the $\alpha$ fiber volume fraction to decrease when the hot rolling temperature increases (Fig. 2b).

b

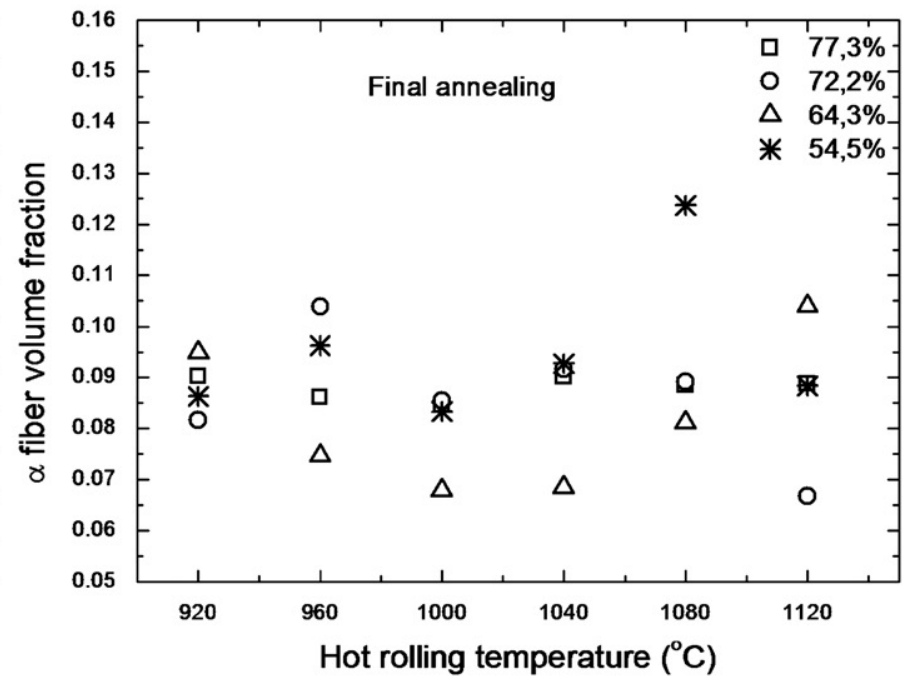

d

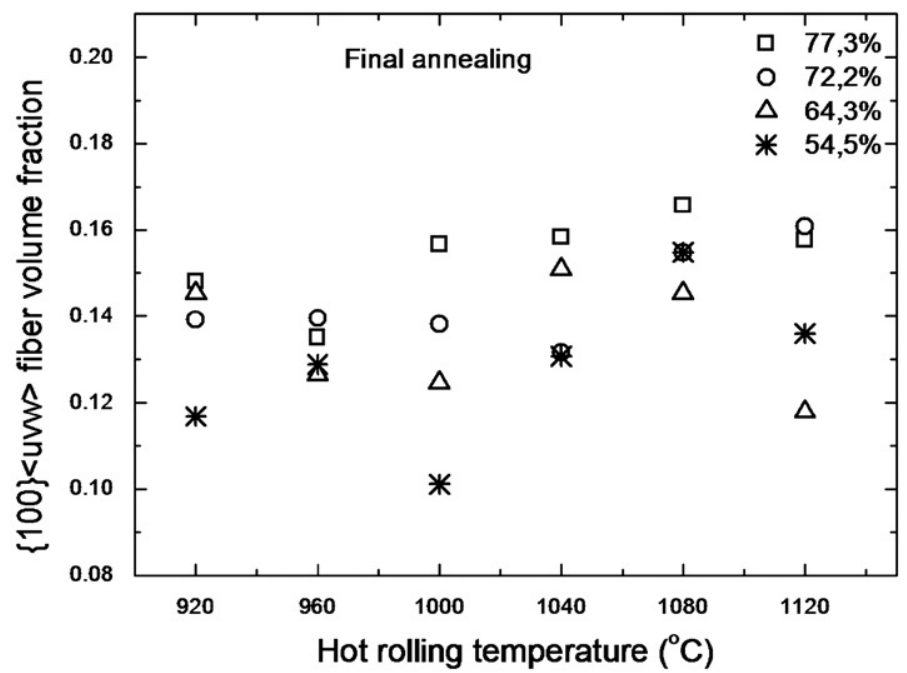

Fig. 6. $\gamma(\mathrm{a}), \alpha(\mathrm{b}), \eta(\mathrm{c})$ and $\{100\}\langle u v w\rangle$ fiber volume fractions as functions of hot rolling temperature and strain degree for the samples annealed. 
The effect of hot rolling temperature and cold strain for the samples as cold rolled on the volume fraction of fibers $\gamma$ and $\alpha$ is shown in Fig. 3. It suggests that rolling temperature practically does not influence the volume fractions of grains with orientations belonging to these fibers. There is an increasing trend of volume fraction $\gamma$ and $\alpha$ with increasing cold strain, when compared with the fractions of these fibers in the samples after hot rolling (Fig. 2). A higher $\gamma$ fiber fraction on work hardened state is interesting because the grains with this orientation store more energy during cold work and increase the tendency to generate shear bands, favoring the nucleation of grains with Goss and Cube orientations during the final annealing [10-12].

The evolution and the recrystallization behavior due to nucleation in shear bands were evaluated by annealing at intermediate temperatures. For the samples submitted to higher cold strain it was observed that the nucleation starts at a lower annealing temperature, because these samples stored more energy during cold deformation. It was also found that the nucleation starts preferentially at shear bands, as shown in Fig. 4.

The semi-quantitative diagram (Fig. 5) was plotted from the microstructures of the samples hot rolled at different temperatures (different grain sizes, Fig. 1) and different cold strains, submitted to five annealings at intermediate temperatures. For each sample, the regions containing shear bands were counted and according to the number and size of these regions, measures of intensity were assigned. This diagram shows an increase in the tendency to form shear bands when the sample has large grain size and was submitted to higher cold strain. It can also be observed that the formation of shear bands has a greater influence of the cold strain than the grain size of samples after hot rolling. Furthermore, it is essential for nucleation of grains with Goss and Cube orientations at the final annealing. A high intensity of shear bands formed in cold rolling improves the magnetic induction and reduces the core losses.

After the final annealing, it is observed that the grain size decreases when the cold strain and the grain size after hot rolling increase. This effect can be explained by the larger work hardening and larger generation of potential sites for nucleation like shear bands, resulting in a smaller final grain size, suggesting a greater difficulty to obtain simultaneously the highest possible magnetic induction and the lowest possible core loss values.

After the final annealing the $\gamma$ fiber volume fraction decreases with increase in the hot rolling temperature (Fig. 6a). The nucleation of grains with orientations belonging to the $\gamma$ fiber takes place preferentially at the grain boundaries [10-12] and an increase in grain size of samples before cold rolling results in a smaller surface area of boundary per unit volume, hindering the $\gamma$ fiber nucleation in annealing. This figure shows that high $\gamma$ volume fraction can be obtained with low cold strain and large grains after hot rolling. This result shows that the cold strain strongly influences the crystallographic texture, as predicted by the semi-quantitative diagram of Fig. 5. The values of $\gamma$ fiber volume fractions in the samples annealed are smaller than those of cold rolled samples, as expected. Samples hot rolled between 1040 and $1120{ }^{\circ} \mathrm{C}$ with cold strains greater than $64.3 \%$ have the lowest fraction values of this fiber.

It was observed for annealed samples that the hot rolling temperature and the cold strain have no significant effect on the volume fraction of grains with $\alpha$ fiber orientations. The highest values of $\eta$ fiber volume fraction were obtained in samples hot rolled from 1000 to $1080{ }^{\circ} \mathrm{C}$ with a $64.3 \%$ of cold strain and hot rolled at $1120{ }^{\circ} \mathrm{C}$ with $72.2 \%$ of cold strain (Fig. 6c). The increase in $\eta$ fiber volume fraction is due to the fact that the samples with large grain sizes and submitted to high cold strain resulted in a greater generation of shear bands, in which grains with orientations belonging to this fiber nucleate preferentially. This result is also consistent with the diagram shown in Fig. 5. The effect of hot rolling temperature and cold strain on the $\left\{\begin{array}{lll}1 & 0 & 0\end{array}\right\}\left\langle\begin{array}{ll}u & v\end{array}\right)$ fiber volume fraction was not significant (Fig. 6d).

As shown in Fig. 7a the increase in hot rolling temperature (or hot rolled grain size), for all the cold strains, improves

a

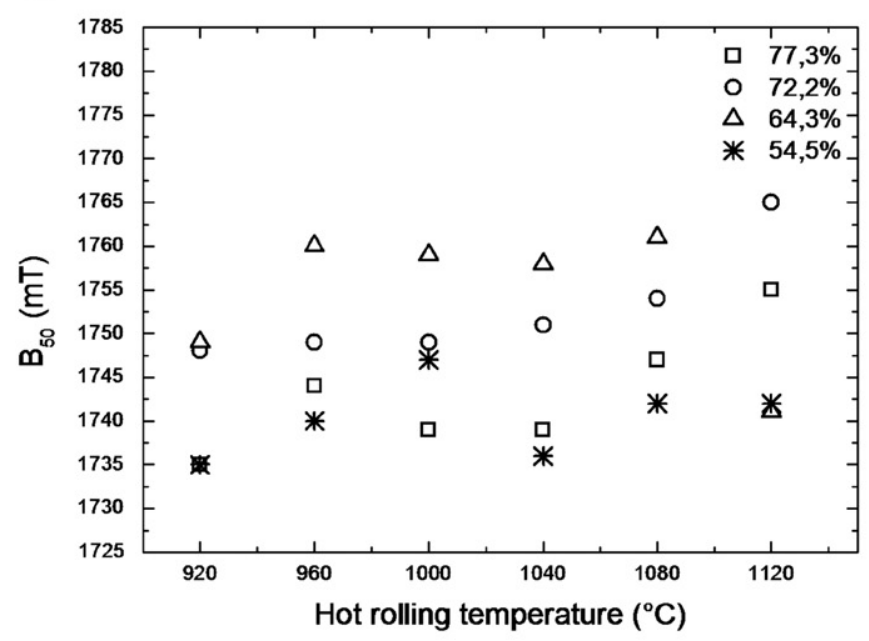

b

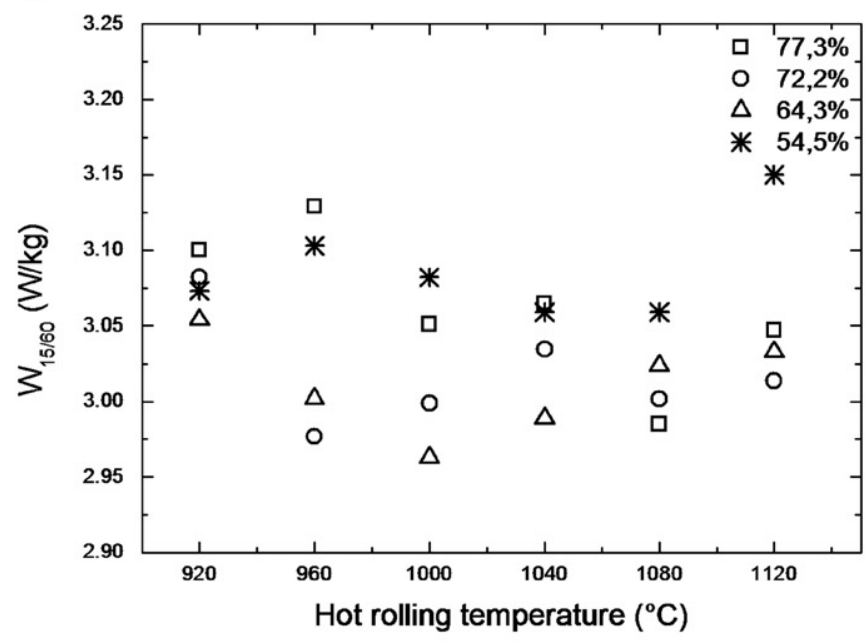

C

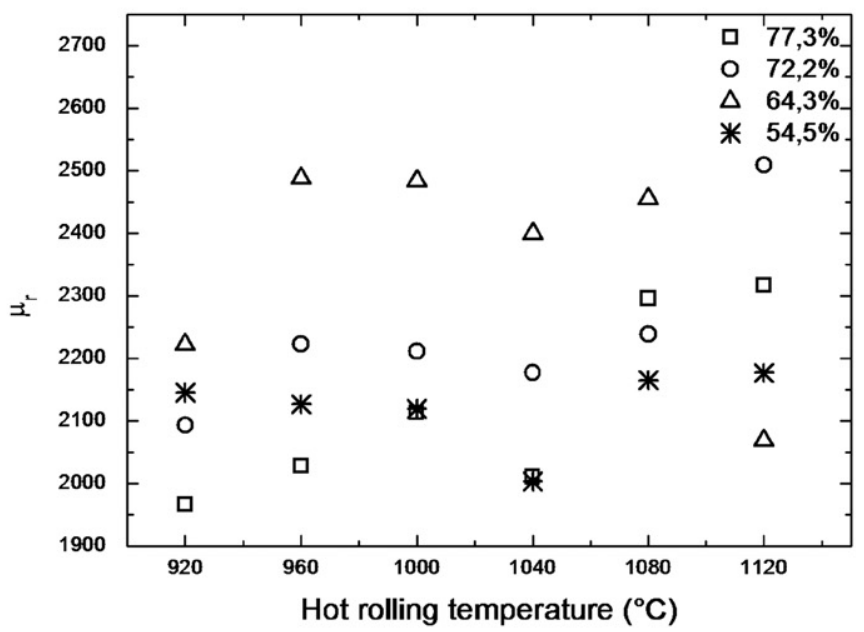

Fig. 7. Magnetic induction at $5000 \mathrm{~A} / \mathrm{m}\left(B_{50}\right)(a)$, magnetic core loss at $1.5 \mathrm{~T} / 60 \mathrm{~Hz}$ $\left(W_{15 / 60}\right)(\mathrm{b})$ and magnetic permeability at $1.5 \mathrm{~T} / 60 \mathrm{~Hz}\left(\mu_{\mathrm{r}}\right)(\mathrm{c})$ as functions of hot rolling temperature and cold strain degree. 
the magnetic induction $B_{50}$ values. This behavior of magnetic induction is according to the literature [9]. In this work the highest magnetic induction value of hot rolled sample was observed at $1120^{\circ} \mathrm{C}, 1.8 \mathrm{~mm}$ thickness and submitted to a cold strain of $72.2 \%$. This result can be predicted by structural analysis (Fig. 5) and is induced by the increase in $\eta$ fiber volume fraction after the final annealing (Fig. 6c), confirming the strong dependence of this property in relation to crystallographic texture. Samples rolled from 1000 to $1080^{\circ} \mathrm{C}$ to $1.4 \mathrm{~mm}$ thickness and $64.3 \%$ of cold strain also showed satisfactory $B_{50}$ values.

The behavior of core loss values at $1.5 \mathrm{~T} / 60 \mathrm{~Hz}\left(W_{15 / 60}\right)$ as a function of hot rolling temperature and cold strain is according to the literature [9] (Fig. 7b). It can be observed that there is a minimum core loss for each hot rolling temperature and this property has a greater dependence on grain size. The sample hot rolled at $1000{ }^{\circ} \mathrm{C}$ to $1.4 \mathrm{~mm}$ thickness and submitted to $64.3 \%$ cold strain showed the lowest core loss value.

Taking into account the results presented for magnetic induction and core losses it can be suggested that the increase in the grain size of the hot rolled samples was beneficial to $B_{50}$, but from a given value this increase leads to a reduction in the final grain size, inducing an undesirable increasing $W_{15 / 60}$.

A tendency of increase in the magnetic permeability $\mu_{\mathrm{r}}$ with increasing hot rolling temperature and the grain size, for all the cold strains is shown in Fig. 7c. It can be observed that the value of magnetic permeability was higher for the sample rolled at $1120{ }^{\circ} \mathrm{C}$ to $1.8 \mathrm{~mm}$ thickness, with $72.2 \%$ cold strain and is induced by the increase in $\eta$ fiber volume fraction after the final annealing (Fig. 6c). However, the samples rolled between 1000 and $1080{ }^{\circ} \mathrm{C}$ to $1.4 \mathrm{~mm}$ thickness and $64.3 \%$ of cold strain also showed satisfactory magnetic permeability values.

\section{Conclusions}

It was found that to obtain the best magnetic properties it is necessary to nucleate grains with favorable texture to the magnetization process, and the high intensity of shear bands generation during the cold rolling is essential. This result can be achieved when getting a large grain size in hot rolled samples at 1000 and $1120{ }^{\circ} \mathrm{C}$ temperatures and submitting them to $64.3 \%$ and $72.2 \%$ cold strain, respectively. However, the best combination of $B_{50}, W_{15 / 60}$ and $\mu_{\mathrm{r}}$ can be obtained by hot rolling the samples at $1000{ }^{\circ} \mathrm{C}$ to $1.4 \mathrm{~mm}$ thickness, with $64.3 \%$ of cold strain.

\section{Acknowledgement}

The authors acknowledge the laboratory support and samples provided for this project by ArcelorMittal Inox Brasil and the financial support by CNPq.

\section{References}

[1] F. Bohn, A. Gündel, F.J.G. Landgraf, A.M. Severino, R.L. Sommer, Magnetostric tion in non-oriented electrical steels, Physica B 384 (2006) 294-296.

[2] S.C. Paolinelli, M.A. Cunha, Effect of the annealing temperature on the structure and magnetic properties of $2 \% \mathrm{Si}$ steel, Materials Research 5 (2002) 373-378.

[3] S.C. Paolinelli, M.A. Cunha, Development of a new generation of high permeability non-oriented silicon steels, Journal of Magnetism and Magnetic Materials 304 (2006) 596-598.

[4] R. Takanohashi, F.J.G. Landgraf, Effect of hot-band grain size and intermediate annealing on magnetic properties and texture of non-oriented silicon steels, Journal of Magnetism and Magnetic Materials 304 (2006) 608-610.

[5] T. Haratani, W.B. Hutchinson, I.L. Dillamore, P. Bate, Contribution of shear banding to origin of Goss texture in silicon steel, Metal Science 18 (1984) 57-65.

[6] J.T. Park, J.A. Szpunar, Evolution of recrystallization texture in nonoriented electrical steels, Acta Materialia 51 (2003) 3037-3051.

[7] F.J. Humphreys, M. Hatherly, Recrystallization and Related Annealing Phenomena, second ed., Elsevier, UK, 2004.

[8] M. Koizumi, H. Inagaki, Role of shear band in texture control of Al-Mg alloys, Metals and Materials 5 (1999) 511-517.

[9] S.C. Paolinelli, M.A. Cunha, A.B. Cota, The influence of shear bands on final structure and magnetic properties of $3 \%$ Si non-oriented silicon steel, Journal of Magnetism and Magnetic Materials 320 (2008) 641-644.

[10] K. Ushioda, W.B. Hutchinson, Role of shear bands in annealing texture formation in 3\%Si-Fe $\left(\begin{array}{lll}1 & 1 & 1\end{array}\right)\left[\begin{array}{lll}1 & 1 & -2\end{array}\right]$ single crystals, ISIJ International 29 (1989) 862-867.

[11] S.C. Paolinelli, M.A. Cunha, Effect of the annealing temperature on the structure magnetic properties of $3 \%$ silicon non-Oriented steel, Journal of Magnetism and Magnetic Materials 254-255 (2003) 379-381.

[12] S.C. Paolinelli, M.A. Cunha, A.B. Cota, The influence of hot rolling finishing temperature on the structure and magnetic properties of $2.0 \% \mathrm{Si}$ non oriented silicon steel, Materials Science Forum 558-559 (2007) 787-792. 